\title{
DESAIN INTERIOR RUMAH TINGGAL RAMAH PENYANDANG CACAT
}

\author{
Dwi Retno Sri Ambarwati* \\ Universitas Negeri Yogyakarta
}

\begin{abstract}
ABSTRAK
Lingkungan yang terorganisir dengan baik akan sangat membantu kesehatan, keamanan dan kemandirian penyandang cacat. Desain interior yang well-designed dapat membantu penyandang cacat melakukan aktivitas. Jenis kecacatan yang berbeda membutuhkan desain yang berbeda sesuai dengan keadaan tiap penyandang cacat.Salah satu aspek penting yang jarang dipertimbangkan dalam perancangan interior yang ramah penyandang cacat adalah pengaturan sirkulasi ruang yang disesuaikan dengan jenis kecacatan. Hal ini menjadikan penyandang cacat tidak memiliki kemandirian dan kualitas hidup. Perancangan interior rumah tinggal yang mendukung kemandirian penyandang cacat meliputi menataan akses masuk bangunan, sirkulasi dan zoning, dimensi dan penataan perabot.
\end{abstract}

Kata Kunci: desain interior, ramah penyandang cacat.

\section{LATAR BELAKANG}

Definisi kecacatan adalah adanya disfungsi atau berkurangnya suatu fungsi yang secara objektif dapat di ukur/ di lihat, karena adanya kehilangan/ kelainan dari bagian tubuh seseorang. Misalnya, tidak adanya tangan, kelumpuhan pada bagian tertentu dari tubuh. Kecacatan ini bisa selalu pada sesesorang, yang dapat menghasilkan perilaku-perilaku yang berbeda pada individu yang berbeda, misalnya kerusakan otak dapat menjadikan individu tersebut cacat mental, hiperaktif, buta, dan lain-lain. Penyandang cacat, berdasarkan Undang-undang no 4 tahun 1997 tentang penyandang cacat (pasal 1 ayat 1) adalah setiap orang yang mengalami kelainan fisik dan mental yang dapat mengganggu atau merupakan rintangan dan hambatan baginya untuk melakukan kegiatan secara selayaknya.

Lebih lanjut disebutkan dalam undang-undang tersebut, bahwa jenis-jenis kecacatan terdiri dari tiga besar, yaitu kecacatan fisik, kecacatan mental, dan kecacatan fisik dan mental (pasal 1 ayat 1). Kecacatan fisik terdiri dari kecacatan tubuh, netra dan rungu wicara. Masing-masing jenis kecacatan tersebut memiliki karakteristik tersendiri. Demikian juga dengan permasalahan yang dihadapinya, sehingga menimbulkan kerentanan terhadap berbagai hal dalam kehidupannya. (Departemen sosial RI. 2009 Pedoman advokasi sosial penyandang cacat. Jakarta: Direktorat Pelayanan Dan Rehabilitasi Sosial Penyandang Cacat)

Penyandang cacat di Indonesia masih dianggap sebagai individu yang memiliki cacat atau kerusakan fisik yang tidak dapat hidup mandiri, perlu dikasihani dan memiliki batasan-batasan dalam berkegiatan. Hal ini membuat para penyandang cacat menjadi "berbeda". Padahal pada UU No 4 tahun 1997, pemerintah mengesahkan bahwa penyandang cacat adalah bagian dari masyarakat Indonesia yang mempunyai kedudukan, hak, kewajiban dan peran yang sama dengan masyarakat Indonesia lainnya di segala aspek kehidupan dan penghidupan. Namun sangat disayangkan, sejak delapan belas tahun UU tersebut dicanangkan realisasi kebijakan ternyata masih jauh dari harapan. Potensi mereka kurang mendapatkan dukungan. Bahkan masih banyak penyandang cacat yang belum mendapatkan kesetaraan baik di lapisan masyarakat hulu maupun hilir. Masyarakat lebih melihat keterbatasan fisik, bukan kemampuan yang dimiliki seseorang.

Salah satu kebutuhan primer manusia adalah papan / rumah untuk tinggal dan kebutuhan ini yang selama ini belum didapatkan oleh kaum penyandang cacat. Saat ini pemerintah masih menjadikan pusat rehabilitasi atau Panti sebagai solusi hunian tinggal bagi penyandang cacat . Namun pusat rehabilitasi menjadikan seakan penyandang cacat adalah sesuatu penyakit yang harus segera diobati.

Penyandang cacat masih dipaksa untuk tinggal di hunian panti atau hunian normal. Padahal hal ini sangat menghambat dan menyulitkan penyandang cacat dalam beraktivitas, bersosialisasi dan menjadi individu yang setara. Sangat sedikit rumah yang dirancang untuk 
memenuhi kebutuhan seorang penyandang cacat . Banyak rumah yang memiliki tantangan arsitektur seperti keberadaan tangga, ruang sempit dan pintu serta hambatan lain yang menyulitkan bagi individu yang dibatasi kursi roda untuk bermanuver. Mereka yang harus hidup dengan kekurangan fisik membutuhkan rumah untuk bisa hidup mandiri seperti orang lain, yang artinya modifikasi dibutuhkan untuk membuat rumah dapat diakses oleh penghuni dengan kursi roda/ cacat fisik yang lain.

Berdasarkan latar belakang di atas, permasalahan dalam penelitian ini adalah bagaimana membuat desain rumah ideal yang dapat ditinggali penyandang cacat dengan mandiri maka diperlukan sebuah panduan rumah ramah cacat sehingga penyandang cacat dapat memperoleh kesetaraan hak dan kesetaraan dalam dengan pemenuhan kebutuhan primer individu yaitu hunian/rumah tinggal.

Adapun tujuan yang ingin dicapai yaitu mendesain rumah ideal yang dapat ditinggali penyandang cacat dengan mandiri, memberikan kesetaraan aksesibilitas bagi kaum penyandang cacat dan menyusun panduan hunian rumah tinggal yang ramah cacat yang layak huni bagi setiap individu penyandang difabilitas.

\section{PENYANDANG CACAT DI INDONESIA}

Selama dasawarsa terakhir, Indonesia mengalami kemajuan yang stabil dalam meningkatkan pendapatan per kapita dan kemajuan besar dalam penghapusan kemiskinan. Namun, negara ini menghadapi tantangan dalam mencapai pembangunan yang merata. Tingkat kemiskinan masih terbilang sangat tinggi dan ketimpangan, terutama bagi masyarakat yang termarjinalisasi dan rentan, termasuk para penyandang disabiltias. Para penyandang cacat kerap kali terisolir secara sosial dan menghadapi diskriminasi dalam akses atas kesehatan dan layanan-layanan lainnya, pendidkan dan pekerjaan. Jumlah penyandang cacat di Indonesia pada tahun 2010 adalah 11.580.117 jiwa.

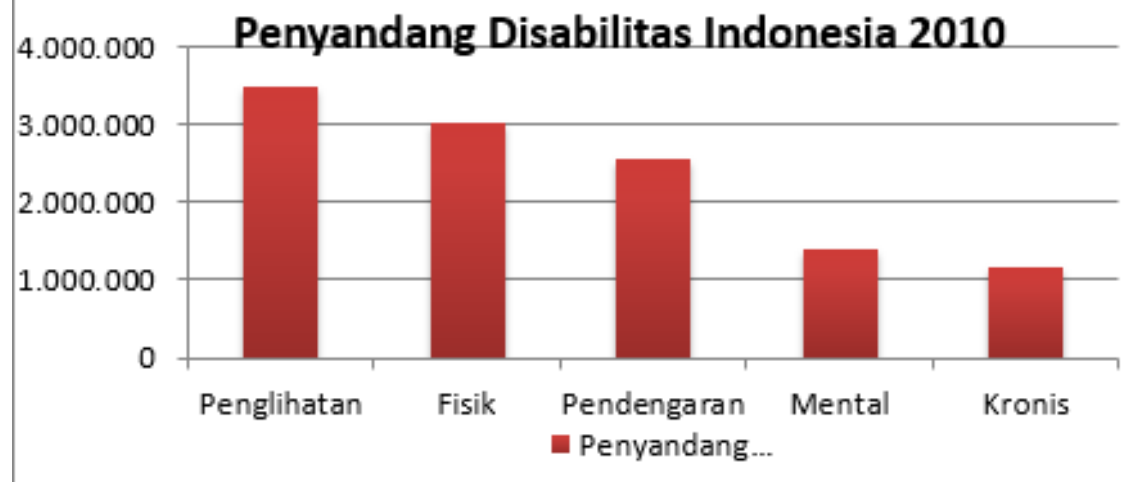

Gambar 1 Grafik Penyandang Cacat Indonesia 2010

(Sumber: PUSDATIN dari Kementerian Sosial 2010)

Sementara menurut data Kementerian Tenaga Kerja dan Transmigrasi, pada 2010 jumlah penyandang cacat adalah 7.126.409 jiwa. Kurang akuratnya data mengenai jumlah penyandang cacat telah menghambat serangkaian aksi dan tindakan yang seharusnya dapat dilakukan. Bahkan tidak terdapat data yang akurat dan mendalam mengenai penyandang cacat di Indonesia.

\section{AKSESIBILITAS UNTUK PENYANDANG CACAT}

Aksesibilitas adalah kemudahan yang disediakan bagi penyandang cacat guna mewujudkan kesamaan kesempatan dalam segala aspek kehidupan dan penghidupan sebagai suatu kemudahan bergerak melalui dan menggunakan bangunan gedung dan lingkungan dengan memperhatikan kelancaran dan kelayakan, yang berkaitan dengan masalah sirkulasi, visual dan komponen setting. Sehingga aksesibilitas wajib diterapkan secara optimal, guna mewujudkan kesamaan kesempatan dalam mencapai segala aspek kehidupan dan penghidupan, menuntut adanya kemudahan dan keselamatan akses bagi semua pengguna tanpa terkecuali (Hendra Arif K.H Lubis). 
Dalam studi tentang hubungan arsitektur lingkungan \& perilaku dalam kaitannya dengan tata ruang, perilaku dioperasionalisasikan sebagai kegiatan manusia yang membutuhkan (tata ruang yang terkait dengan kegiatan) atau wadah kegiatan yang berupa ruang. Sedangkan ruang diartikan sebagai suatu petak yang dibatasi oleh dinding dan atap baik oleh unsur yang permanen ataupun tidak permanen. Dalam kaitannya dengan manusia, hal paling penting dari pengaruh ruang terhadap perilaku manusia adalah fungsi atau pemakaian dari ruang tersebut.

(https://www.academia.edu/18975931/keterkaitan_manusia_dan_arsitektur).

Aksesibilitas adalah kemudahan bergerak melalui dan menggunakan lingkungan. Halhal yang berkaitan dengan aksesibilitas adalah bangunan, elemen bangunan, kamar kecil (toilet), pintu, ramp, ruang, ruang lantai bebas, rute aksesibel, tangga (Holmes, James, 1998). Asas fasilitas dan aksesibilitas tersebut menurut Peraturan Menteri Pekerjaan Umum No. 30/PRT/M/2006 tentang Pedoman Teknis Fasilitas dan Aksesibilitas pada Bangunan Gedung dan Lingkungan meliputi:

- Keselamatan, yaitu setiap bangunan yang bersifat umum dalam suatu lingkungan terbangun, harus memperhatikan keselamatan bagi semua orang.

- Kemudahan, yaitu setiap orang dapat mencapai semua tempat atau bangunan yang bersifat umum dalam suatu lingkungan.

- Kegunaan, yaitu setiap orang harus dapat mempergunakan semua tempat atau bangunan yang bersifat umum dalam suatu lingkungan.

- Kemandirian, yaitu setiap orang harus bisa mencapai, masuk dan mempergunakan semua tempat atau bangunan yang bersifat umum dalam suatu lingkungan dengan tanpa membutuhkan bantuan orang lain. berikut:

Beberapa pertimbangan desain rumah ramah cacat secara garis besar adalah sebagai

- Jalan yang aman dan bebas langkah perjalanan yang aman dari pintu masuk dan / atau area parkir ke pintu masuk tempat tinggal yang sejajar

- Setidaknya satu atau tanpa level lantai untuk masuk ke dalam hunian.

- pintu dan koridor yang memudahkan pergerakan yang nyaman antar ruang.

- Sebuah toilet di lantai bawah yangmenyediakan akses mudah dijangkau tanpa naik tangga.Kamar mandi dengan lantai tanpa level

- Dinding di sekitar toilet, shower dan bak mandi yang diperkuat untuk mendukung pemasangan kabel yang aman di kemudian hari

- Pegangan terus menerus di satu sisi tangga yang yang naiknya lebih dari satu meter. (Livable Housing Australia, 2nd Edition. 2012)

\section{METODE}

Prosedur pengembangan yang dilakukan dalam penelitian ini menganut prosedur R \& D Borg \& Gall (2003) prosedur penelitian meliputi langkah berikut.

1. Studi pendahuluan, informasi dan standarisasi tentang kebutuhan desain interior ruang ramah cacat dari pustaka dan kebutuhan kemandirian pengguna di lapangan. Kegiatan dilakukan dengan observasi dan FGD.

2. Melakukan perancangan dan draf kasar meliputi: meliputi konsep ruang ramah cacat, aktifitas, fasilitas, material, gambar kerja dan prototype.

3. Membuat draf produk (produk awal) berupa draf panduan interior ruang ramah cacat.

4. Melakukan validasi ahli terhadap draf produk.

5. Melakukan penyempurnaan draf produk

\section{PEMBAHASAN}

\section{Akses Ke Dalam Gedung}

Dari latar belakang yang telah dijelaskan di atas maka penyandang cacat sangat membutuhkan sebuah akses yang harus didesain dengan mempertimbangkan keterbatasan mobilitas 
para penyandang cacat, baik menggunakan alat bantu berupa kursi roda maupun alat bantu lainnya. Sehingga unsur-unsur yang harus ada di pintu sebagai akses masuk adalah:

1. Sebuah rak dengan tinggi $900 \mathrm{~mm}$ untuk menempatkan barang bawaan.

2. Sebuah kursi setinggi $450 \mathrm{~mm}$ untuk peralihan duduk dari kursi ke kursi roda

3. Sebuah jalan setapak dengan pencahayaan

4. Sebuah panel atau ikan-mata lensa kaca di pintu untuk melihat pengunjung

5. Sebuah jalan setapak dengan kemiringan maksimum 1:20 dan permukaan tahan tergelincir

6. Lebar pintu yang digunakan adalah $120 \mathrm{~cm}$ untuk memberi alokasi rung untuk kedua bahu.

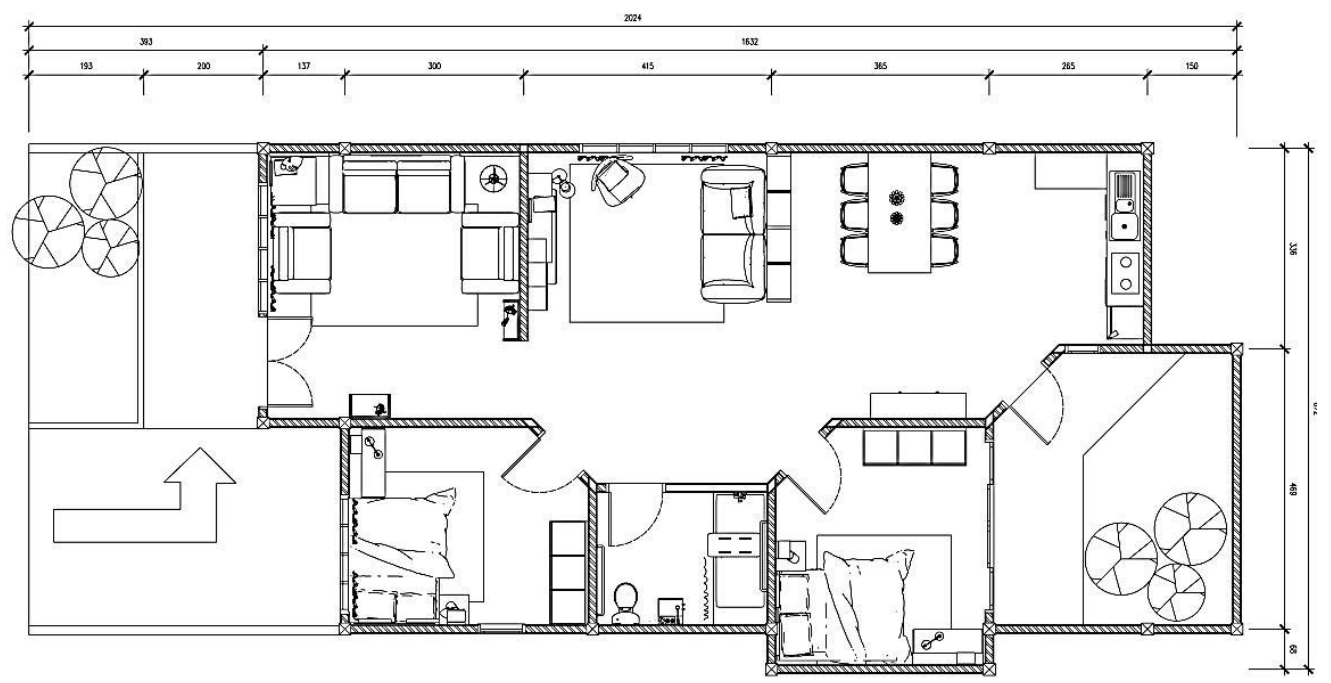

Gambar 2 Denah dan Tampak Rumah Difable (Gambar: Dwi Retno SA, 2017)

\section{Akses untuk ke Ruangan yang Lebih Tinggi}

Pangguna kursi roda membutuhkan permukaan lantai datar, kalaupun harus ada kemiringan harus sangat landai tidak boleh lebih 5 persen untuk dapat untuk dapat dilalui kursi roda secara mandiri tanpa bantuan orang lain untuk mendorong. Kemniringan yang curam akan membatasi penggunaan kursi roda secara mandiri sehingga tidak boleh digunakan karena berbahaya tidak hanya untuk pengguna kursi roda tetapi juga untuk orang orang tua.

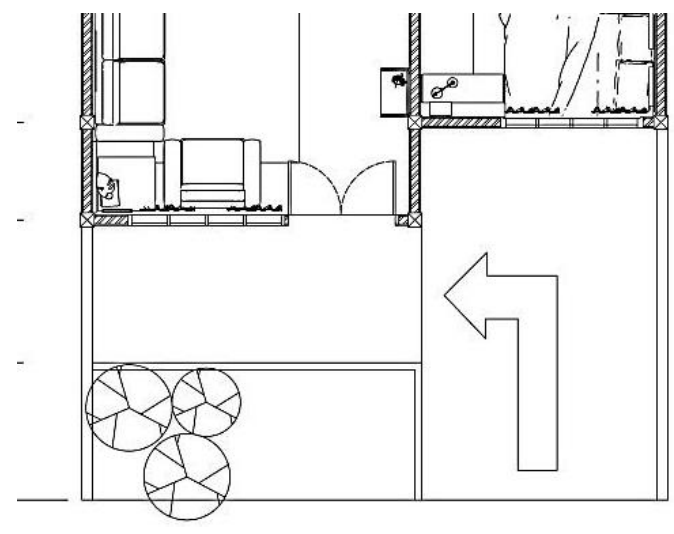

Gambar 3 Akses berupa Tangga/tanjakan (Gambar: Dwi Retno SA, 2017) 


\section{Koridor dan Akses Bersama}

Desain koridor harus memungkinkan pengguna kursi roda untuk bergerak dengan nyaman. Dimensi koridor yang baik minimal $120 \mathrm{~cm}$. Agar pengguna lebih merasa nyaman dalam memutar kursi roda, lebar koridor dibuat $1.5 \mathrm{~m}$.

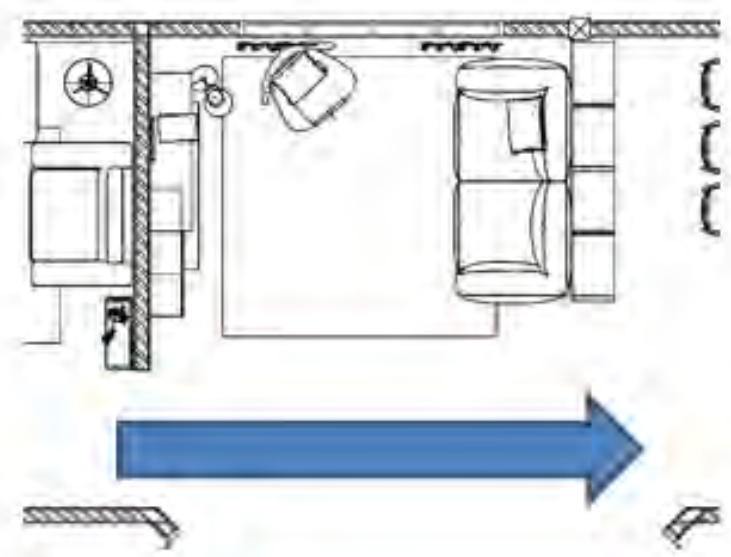

Gambar 4 Akses berupa koridor dari ruang tamu ke ruang keluarga (Gambar: Dwi Retno SA, 2017)

\section{Kamar Mandi / Toilet}

Persyaratan untuk akses di kamar mandi dan toilet sangatlah penting. Ukuran minimum, ruang untuk toilet dan kamar mandi harus 2,40 m x 2,30 m, itu digunakan untuk pergerakan memutar berupa diameter 1,5 meter.

WC dan wastafel harus ditempatkan pada sudut $90^{\circ}$, dengan demikian jarak antara dua tempat dapat dijangkau untuk mengoperasikan air ketika sedang memakai WC. Pemakaian handriil sebagai sekat antara WC dengan wastafel sangat membantu dalam pegangan untuk pengguna kursi roda.

Dimensi prabotan yang ada di kamar mandi sebagai berikut:

1. Tinggi WC: $0,48 \mathrm{~m}$ di atas lantai.

2. Lebar WC: $0,80 \mathrm{~m}$.

3. Tinggi Wastafel: $0,80 \mathrm{~m}$ di atas lantai.

4. Lebar wastafel: $0,60 \mathrm{~m}$.

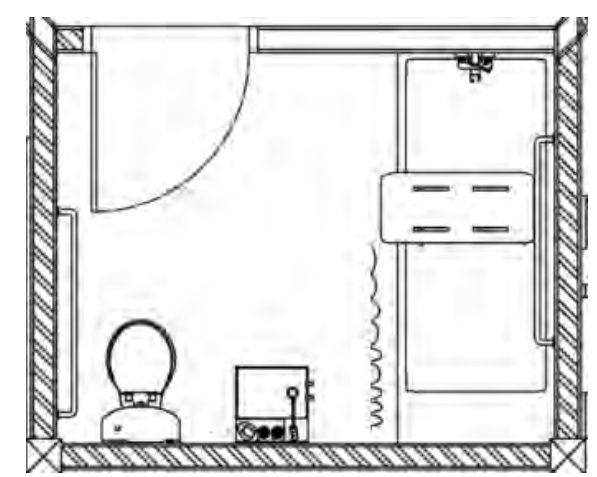

Gambar 5 Desain Kamar mandi (Gambar: Dwi Retno SA, 2017)

Kesimpulannya yang dibutuhkan adalah ruang sirkulasi yang memungkinkan untuk gerakan tubuh dan gerakan kursi roda. 


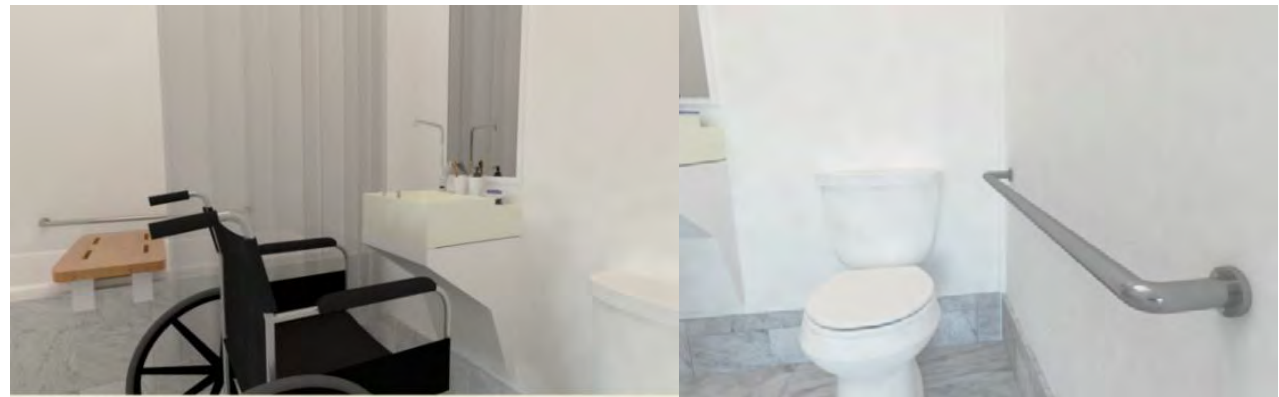

Gambar 6. Perspektif kamar mandi

(Gambar: Dwi Retno SA, 2017)

\section{Pintu Dan Jendela}

Mendesain pintu sebaiknya menggunakan pintu yang arah bukanya keluar atau pintu dengan engsel berayun (push and pull). Ini dimaksudkan untuk memaksimalkan akses jika seseorang terjebak keruntuhan terhadap pintu, tubuh mereka tidak akan mencegah seseorang membuka pintu dan masuk untuk membantu mereka. Jendela ganda harus memiliki ventilasi yang baik dan tidak menonjol ke dalam ruang.

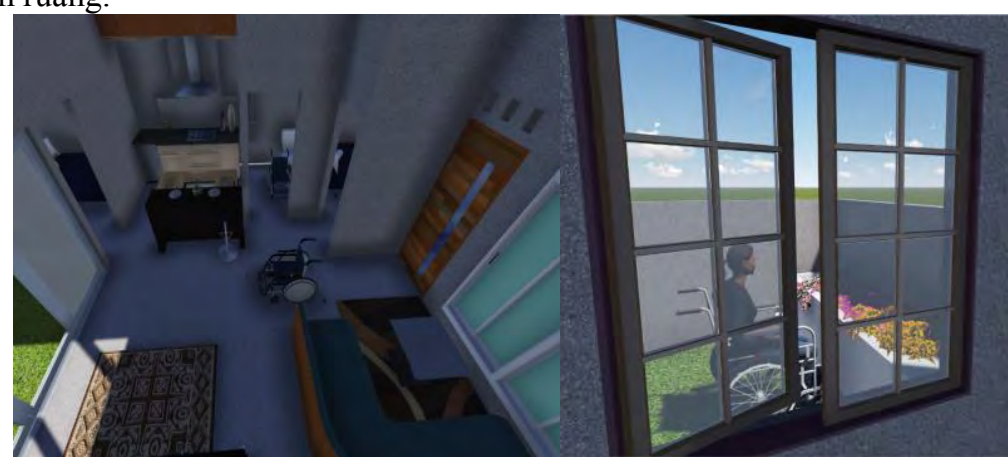

Gambar 7 Akses berupa pintu dan jendela

\section{Kamar Tidur}

Penataan bagi kamar tidur penyandang cacat pada intinya sama saja dengan penataan pada kamar tidur orang normal, hanya saja perbedaaan terletak pada sirkulasinya. Penyandang cacat memiliki ukuran dan dimensi standard untuk penempatan sirkulasi. Ukuran dasar penataan inilah yang dijadikan standard dalam penempatan dan perancangan sirkulasi bagi penyandang cacat. Kamar yang digunakan sebagai contoh berukuran $3.5 \mathrm{~m} \times 4 \mathrm{~m}$.

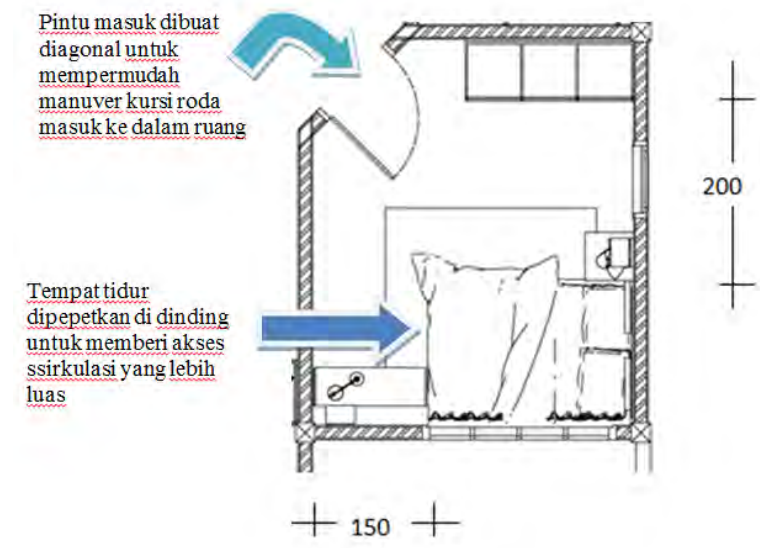

Gambar 8 Denah Ruang Tidur (Gambar: Dwi Retno SA, 2017) 


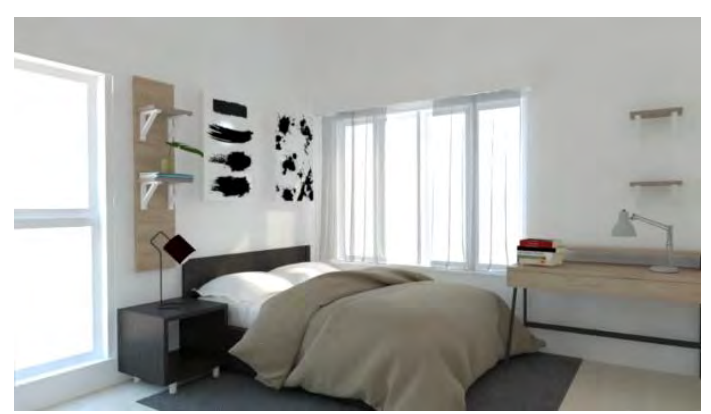

Gambar 9 Perspektif Ruang Tidur

(Gambar: Dwi Retno SA, 2017)

Ruang sirkulasi di depan pintu kamar minimal memiliki luasan area $150 \mathrm{~cm} \times 150$ cm.Penggunaan pintu geser atau pintu dorong tarik untuk memudahkan gerakan buka-tutup dan untuk menghemat ruangan dengan lebar pintu usahakan $>100 \mathrm{~cm}$.

Untuk memudahkan akses usahakan penempatan pintu dan ruang di sebelah tempat tidur sejalur. Space ruang sirkulasi antara tempat tidur dan dinding berjarak $150 \mathrm{~m}$, berguna untuk memberi ruang untuk akses ke tempat tidur dan melakukan gerakan berputar. Menurut standart yang berlaku minimum area yang digunakan untuk kursi roda adalah $121,9 \mathrm{~cm}$ x $121,9 \mathrm{~cm}$. Tata letak kamar yang baik dan nyaman bagi pengguna kursi roda harus ada ruang untuk mobilitas memutar dengan diameter 1.5 meter.Unsur tata letak kamar tidur yang nyaman bagi pengguna kursi roda sebagai cukup ruang untuk bergerak, dekat dengan kamar mandi dan pencahayaan dan ventilasi alami yang baik

\section{Tata Letak Dapur}

Dapur untuk penyandang cacat membutuhkan lebih banyak pertimbangan dan perhatian dibanding ruangan lain. Berbeda dengan ruang tamu, dapur membutuhkan ruang yang lebih lebar dibanding orang normal.

Tujuan tata letak dapur adalah memudahkan akses dan mobilitas para pengguna kursi roda dalam memasak. Tata letak tersebut diilustrasikan pada gambar. Unsur tata letak dapur yang baik bagi pengguna kursi roda, sebagai berikut: Ruang bangku di sisi wastafel, ruang lutut, bagian wastafel untuk mencuci piring dan mengeringkan piring.

Ketinggian maksimal pantry adalah $1450 \mathrm{~mm}$ untuk pengguna kursi roda.Lebar pantry minimum $1000 \mathrm{~mm}$, kedalaman pantry $600 \mathrm{~mm}$ sebagai standar ukuran furnitur. Beberapa rak kecil di dalam pintu dapat diatur. Sebuah pembukaan atau akses berkisar $900 \mathrm{~mm}$ dibuat untuk akses yang lebih mudah.

Ketinggian maksimal pantry adalah $1450 \mathrm{mmb}$ untuk pengguna kursi roda.Lebar pantry minimum $1000 \mathrm{~mm}$, kedalaman pantry $600 \mathrm{~mm}$ sebagai standar ukuran furnitur. Beberapa rak kecil di dalam pintu dapat diatur. Sebuah pembukaan atau akses berkisar $900 \mathrm{~mm}$ dibuat untuk akses yang lebih mudah.

Dapur sebaiknya bersebelahan dengan ruang keluarga/ ruang makan. Peralatan dan pengaturan harus memfasilitasi persiapan makanan dan pembersihan yang cepat dan fungsional. Dapur harus direncanakan dan dirancang agar bermanfaat dalam membuat persiapan makanan, dan dalam melakukan berbagai kegiatan penghuni rumah tinggal. 


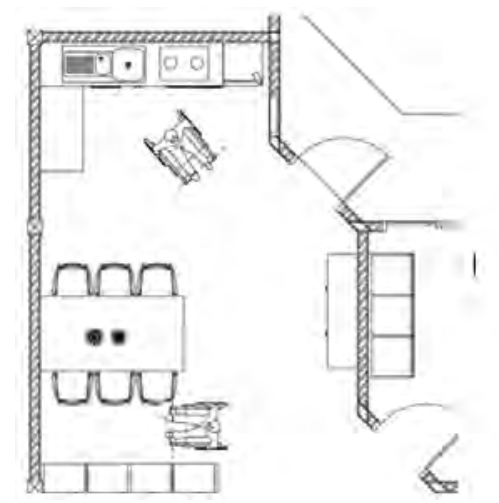

Gambar 10 Denah Dapur yang aksesibel (Gambar: Dwi Retno SA, 2017)

Pintu masuk dapur harus direncanakan untuk mengakomodasi sirkulasi keluar masuk dapur. Lantai dan permukaan dinding harus dari bahan yang tidak licin dan mudah dibersihkan. Lemari dinding harus memiliki rak yang dapat disesuaikan. Setidaknya satu lemari, dengan kunci, untuk penyimpanan persediaan pokok harus disediakan, serta lemari untuk pel, sapu, dan bahan pembersih. Lebar minimum $200 \mathrm{~cm}$ harus disediakan antara kursi roda dengan meja dapur atau dengan dinding

\section{KESIMPULAN}

Merancang rumah untuk orang cacat fisik tidak berarti rumah itu harus seperti rumah sakit. Meski fungsinya harus menjadi fitur yang paling penting, ada banyak penyesuaian yang bisa dilakukan untuk membuat hidup lebih aksesibel dan dapat mempermudah penyandang cacat untuk menjalani hidupnya dengan mandiri.

Membangun bagi lingkungan hidup dan manusia juga berarti membangun bagi penyandang cacat, sebuah fasilitas yang dapat dinikmati penyandang cacat tentunya juga dapat dinikmati oleh masyarakat secara luas. Dalam dunia arsitektur, perancangan tidak hanya bagi masyarakat normal saja, masyarakat penyandang cacat yang juga membutuhkan bantuan merupakan salah satu objek yang menjadi bahan pertimbangan aspek perancangan. Untuk itu panduan ini dibuat sebagai bahan masukan bagi perancangan rumah tinggal bagi orang yang memiliki kekurangan fisik, dalam hal ini orang tuna netra dan yang menggunakan kursi roda.

\section{DAFTAR PUSTAKA}

Verwer, Peter, et.al. 2012, Livable Housing Australia Guidelines, 2nd Edition. Livable Housing Design: Sydney.

Peraturan Menteri Pekerjaan Umum No. 30/PRT/M/2006 tentang Pedoman Teknis Fasilitas dan Aksesibilitas pada Bangunan Gedung dan Lingkungan.

Departemen sosial RI. 2009 Pedoman Advokasi Sosial Penyandang Cacat. Jakarta: Direktorat Pelayanan Dan Rehabilitasi Sosial Penyandang Cacat

https://www.academia.edu/18975931/keterkaitan_manusia_dan_arsitektur 